\title{
Modeling human trophoblast, the placental epithelium at the maternal fetal interface
}

\author{
Mariko Horii ${ }^{1,2}$, Ojeni Touma ${ }^{1,2}$, Tony Bui ${ }^{1,2}$ and Mana M Parast ${ }^{1,2}$ \\ ${ }^{1}$ Department of Pathology, University of California San Diego, La Jolla, California, USA and ${ }^{2}$ Sanford Consortium for \\ Regenerative Medicine, University of California San Diego, La Jolla, California, USA
}

Correspondence should be addressed to M M Parast; Email: mparast@ucsd.edu

\begin{abstract}
Appropriate human trophoblast lineage specification and differentiation is crucial for the establishment of normal placentation and maintenance of pregnancy. However, due to the lack of proper modeling systems, the molecular mechanisms of these processes are still largely unknown. Much of the early studies in this area have been based on animal models and tumor-derived trophoblast cell lines, both of which are suboptimal for modeling this unique human organ. Recent advances in regenerative and stem cell biology methods have led to development of novel in vitro model systems for studying human trophoblast. These include derivation of human embryonic and induced pluripotent stem cells and establishment of methods for the differentiation of these cells into trophoblast, as well as the more recent derivation of human trophoblast stem cells. In addition, advances in culture conditions, from traditional two-dimensional monolayer culture to 3D culturing systems, have led to development of trophoblast organoid and placenta-on-a-chip model, enabling us to study human trophoblast function in context of more physiologically accurate environment. In this review, we will discuss these various model systems, with a focus on human trophoblast, and their ability to help elucidate the key mechanisms underlying placental development and function. This review focuses on model systems of human trophoblast differentiation, including advantages and limitations of stem cell-based culture, trophoblast organoid, and organ-on-a-chip methods and their applications in understanding placental development and disease.

Reproduction (2020) 160 R1-R11
\end{abstract}

\section{Introduction}

Trophoblast (derived from the Greek word 'tropho,' meaning to feed) is the epithelial cell in the placenta, a transient organ which plays a pivotal role in fetal growth and development during pregnancy. Understanding trophoblast differentiation is crucial for unraveling placental development and function across gestation, as well as placenta-based complications of pregnancy. Abnormal trophoblast differentiation has been associated with numerous pregnancy complications, including recurrent miscarriage, preeclampsia, and fetal growth restriction (Jauniaux et al. 2006, Norwitz 2006, Romero et al. 2011).

Placental epithelium is derived from the trophectoderm - the outer layer of the preimplantation blastocyst-stage embryo, which gives rise to three distinct trophoblast subtypes. Cytotrophoblast (CTB) are considered proliferative stem/progenitor cells. Within floating villi, CTBs undergo cell-cell fusion to form a multinucleated syncytiotrophoblast (STB), which secretes human chorionic gonadotropin (hCG), placental lactogen (hPL, also called chorionic somatomammotropin hormone or $\mathrm{CSH}$ ), and pregnancy-specific glycoproteins (PSGs), and is involved in nutrient/gas exchange. Within trophoblast cell columns of anchoring villi, CTBs differentiate into extravillous trophoblast (EVT), a highly motile cell type which invades the maternal uterine wall to remodel spiral arteries and establish blood supply to the fetoplacental unit (Bischof \& Irminger-Finger 2005, James et al. 2012).

As the most evolutionarily divergent organ, the human placenta, and specifically human trophoblast, have been difficult to study, mostly due to the lack of reproducible and widely available model systems which accurately represent these cells in vivo. However, a combination of recent advances in regenerative medicine has greatly expanded our ability to model this important cell type at the maternal-fetal interface. These include 1) the ability to reprogram a wide range of somatic cell types into induced pluripotent stem cells (iPSCs) (Takahashi et al. 2007), which can subsequently be differentiated into trophoblast (Amita et al. 2013, Horii et al. 2016), and 2) establishment of culture conditions for growth and expansion of both human trophoblast stem cells (hTSC) (Okae et al. 2018) and self-replicating human placental organoids (Haider et al. 2018, Turco et al. 2018). Most recently, several groups have also brought together various cell types to develop placenta-on-a-chip models (Blundell et al. 2016, Arumugasaamy et al. 2018, Nishiguchi et al. 2019). In 
this review, we will describe these recent advances, detailing the advantages and limitations of each model system and placing them in the larger context of both the past and future of this important area of reproduction. We have included a list of abbreviations commonly used in this review in Table 1.

\section{Human trophoblast lineage specification and early placental development}

Much of what we know about trophectoderm (TE) establishment comes from studies in mice, which have identified a primary role for the Hippo signaling pathway in this process (Nishioka et al. 2009). Specifically, this pathway is turned off in the outer (TE) cells of latestage morula, leading to formation of a Tead4-Yap1 complex, which subsequently induces $\mathrm{Cdx} 2$, a master switch of TE cell fate (Strumpf et al. 2005). Downstream of $\mathrm{Cdx} 2$, other transcription factors are induced, including Eomes and Elf5, which help to maintain proliferative mouse trophoblast stem cells (mTSC) within the extraembryonic ectoderm layer of the early post-implantation embryo (Russ et al. 2000, Donnison et al. 2005, Senner \& Hemberger 2010). Gata2 and Gata3 transcription factors have also been found to play significant, albeit redundant, roles in establishment of TE (Home et al. 2017).

Little is known about the mechanism(s) behind specification of TE in the human embryo. Recent studies, using a combination of immunostaining and single-cell RNAseq, have identified significant differences in marker expression between mouse and human preimplantation embryos, including absence of ELF5 and EOMES in human TE (Niakan \& Eggan 2013, Yan et al. 2013, Blakeley et al. 2015, Petropoulos et al. 2016). In addition, several lines of evidence, including a prolonged period during which the pluripotency marker POU5F1/OCT4 and the TE marker CDX2 are co-expressed in the TE layer, suggest that human TE is not specified until at least the late blastocyst stage (Niakan et al. 2012, Niakan \& Eggan 2013). In fact, TE cells, taken from a day 5 human blastocyst and repositioned into the center of the same embryo, did not sort back to their original position and induced expression of NANOG, an epiblast marker (De Paepe et al. 2013). Furthermore, while Pou5F1/Oct4 is not involved in TE specification in mouse, the targeted knockout of its ortholog in the human blastocyst was found to affect gene expression in both the epiblast and TE compartments (Fogarty et al. 2017). Finally, methods have been developed allowing human embryos to transition from pre- to post-implantation stages in vitro (Deglincerti et al. 2016, Shahbazi et al. 2016); these studies have shown GATA3 to be the most uniform marker of human TE, with CDX2 expressed less consistently among TE cells. While all the previously mentioned data point to numerous differences in mechanism(s) of TE fate specification in the human embryo, the exact sequence of events, including the transcriptional networks and signaling pathways involved, remain obscure.

Even less is known about events surrounding implantation of the human embryo, which begins at $\sim 7$ days post-fertilization. Studies by Hertig and Rock led to the first observations of this crucial period of development (Hertig et al. 1954, 1956); however, most other knowledge of these events has arisen from in vitro culture of human embryos, performed, in large part, in context of fertility treatment. Studies using human endometrial epithelial monolayers have shown that, in contrast to mouse embryos, the initial attachment of human embryos occurs via the polar TE, cells located adjacent to the inner cell mass (Lindenberg et al. 1989). Subsequently, the embryo appears to dive underneath the endometrium, where, surrounded by endometrial stroma, the TE layer begins to expand and differentiate, giving rise to an inner layer of mononuclear cytotrophoblast (CTB) and an outer layer of primitive syncytium (Hertig et al. 1956, Boyd \& Hamilton 1970). The latter cells are unusual in that, while multinucleated, they appear to be highly invasive, located at the forefront of the burrowing embryo; these cells should be distinguished from definitive syncytiotrophoblast, cells which arise slightly later in gestation, through cell-cell fusion of CTB.

Within a few days following implantation, primary villi begin to form through invagination of the CTB layer; these are subsequently invaded by mesenchymal

Table 1 List of abbreviations.

\begin{tabular}{|c|c|}
\hline Abbreviation & Definition \\
\hline BAP & Combination of $\underline{B} M P 4, \underline{A} 83-01$, and $\underline{P D} 173074$ \\
\hline BMP4 & Bone morphogenetic protein-4 \\
\hline СТВ & Cytotrophoblast \\
\hline $\mathrm{EB}$ & Embryoid bodies \\
\hline EpiSC & Epiblast stem cells \\
\hline ESC & Embryonic stem cells \\
\hline EVT & Extravillous trophoblast \\
\hline FGF4 & Fibroblast growth factor- 4 \\
\hline GPI & Glycosyl-phosphatidyl-inositol \\
\hline hCG & Human chorionic gonadotropin \\
\hline HIF & Hypoxia-inducible factor \\
\hline HLA & Human leukocyte antigen \\
\hline $\mathrm{hPL}$ & Human placental lactogen \\
\hline hPSC & $\begin{array}{l}\text { Human pluripotent stem cells (includes } \\
\text { iPSC and hESC) }\end{array}$ \\
\hline $\mathrm{ICM}$ & Inner cell mass \\
\hline iPSC & Induced pluripotent stem cells \\
\hline iTSC & Induced trophoblast stem cells \\
\hline LIF & Leukemia inhibitory factor \\
\hline MACS & Magnetic-activated cell sorting \\
\hline MEF & Mouse embryonic fibroblast/feeders \\
\hline MEF-CM & $\begin{array}{l}\text { Mouse embryonic fibroblast/ } \\
\text { feeder-conditioned media }\end{array}$ \\
\hline MSC & Mesenchymal stem cells \\
\hline PSG & Pregnancy-specific glycoprotein \\
\hline STB & Syncytiotrophoblast \\
\hline TE & Trophectoderm \\
\hline TGF $\beta$ & Transforming growth factor beta \\
\hline TSC & Trophoblast stem cells \\
\hline
\end{tabular}

https://rep.bioscientifica.com 
cells and eventually by fetal blood vessels and undergo branching morphogenesis, leading to formation of mature chorionic villi, the functional units of the human placenta (Benirschke et al. 2012). Within the placental disc, floating chorionic villi, lined by an outer layer of multinucleated syncytiotrophoblast (STB), serve as the exchange interface for gases and nutrients. At the basal plate (the maternal surface of the placental disc), anchoring villi attach to the uterine wall through trophoblast cell columns, structures composed of a progression of CTB differentiating into extravillous trophoblast (EVT) (Benirschke et al. 2012). Mature EVT are highly motile cells, which invade through the decidualized uterine stroma and up to the inner onethird of the myometrium, remodeling maternal spiral arterioles in order to optimally supply the fetoplacental unit with maternal blood (Benirschke et al. 2012).

\section{Traditional models for study of human trophoblast differentiation}

Placental explants can be generated from placental tissues of any gestation. Although numerous culture conditions and uses have been described (reviewed by Miller et al. 2005), generally speaking, explants from first trimester placenta, cultured on collagen I, are often used for study of EVT differentiation and secretory/ invasive functions (Knöfler \& Pollheimer 2013), while those from later gestation/term placenta, cultured on tissue culture inserts, are generally used to study STB function, including its secretion of various hormones and generation of extracellular vesicles (Fitzgerald et al. 2018, Tong \& Chamley 2018). Dual EVT/STB differentiation has also been achieved from first trimester placental explants, by first stripping of the STB layer to expose the underlying CTB, followed by culture under different oxygen tensions or growth factors to generate either EVT or STB (Caniggia et al. 2000, Baczyk et al. 2006). However, the disadvantage of these models is the presence of a mixed cell type, which makes it difficult to assess or manipulate gene expression in a cell typespecific manner. For this reason, researchers have turned to trophoblast isolation, specifically isolation of CTB, the trophoblast progenitor cell type.

Using the 'Kliman' method (a series of enzymatic digests followed by Percoll gradient centrifugation), or variations thereof, CTB can be isolated, which are relatively pure, and can be plated to generate either EVT/ STB (from first trimester placenta) or STB alone (from later gestation/term placenta) (Kliman et al. 1986, Fisher et al. 1989). Our own studies have pointed to oxygen tension, through hypoxia-inducible factor (HIF), regulating the switch between STB and EVT differentiation of first trimester CTB cultured on fibronectin (Wakeland et al. 2017). In addition, gene expression can be manipulated in purified CTB, as these cells are susceptible to transduction by lentivirus, at least within a few hours of plating (Chen et al. 2006, Wakeland et al. 2017). However, CTB isolations can be problematic, resulting in low or variable yields and purity, thus requiring additional steps (i.e. using magnetic-activated cell sorting or MACS for further purification) prior to use. Also, since they have a limited life span, at least by traditional culture methods, fresh cell isolates are needed for each new experiment, requiring continuous access to viable placental tissues, which can be difficult, particularly for early gestation tissues. For this reason, researchers have turned to established human trophoblast cell lines, of which multiple have been generated over the years.

Trophoblast cell lines include those generated by immortalization, such as HTR8/SVneo and SW71 cell lines, generated by introduction of either the simian virus large T antigen or hTERT into first trimester trophoblast (Graham et al. 1993, Straszewski-Chavez et al. 2009). Other widely used trophoblast cell lines include BeWo and JEG3 cell lines, derived from gestational choriocarcinoma, a biphasic trophoblastic tumor (Cerneus \& van der Ende 1991). However, these cells are suboptimal for studying trophoblast differentiation, as they can only mimic specific phenotypes of either EVT or STB, rather than be stimulated to differentiate from a progenitor to a terminally differentiated phenotype. In addition, while these cells are easy to culture and manipulate and provide a much-needed starting point for evaluation of gene regulation and signaling pathways within the trophoblast compartment, they have abnormally amplified and/or aneuploid genomes and there are significant gaps between their phenotypes and those of bona fide trophoblast cells in vivo (Apps et al. 2009, Bilban et al. 2010). For these reasons, and in order to establish a consistent, widely accessible model of human trophoblast differentiation starting with normal diploid cells, several groups have turned to the use of pluripotent stem cells for study of trophoblast differentiation.

\section{Pluripotent stem cells as a model of human trophoblast differentiation}

The first derivation of human embryonic stem cell (hESC) lines from outgrowths of preimplantation human blastocysts was reported by Thomson's group in 1998 (Thomson et al. 1998). Shortly thereafter, Xu et al. (2002) reported that hESC can differentiate into hCG-secreting multinucleated cell, resembling placental STB, using feeder-conditioned media (FCM) supplemented with bone morphogenetic protein-4 (BMP4). An analogous observation was made when Gerami-Naini et al. reported secretion of hCG, estradiol, and progesterone from hESC-derived embryoid bodies (EBs) grown in suspension and then transferred onto Matrigel (GeramiNaini et al. 2004). Since then, multiple groups, including ours, have confirmed the ability of hESC and, later, that of 
induced pluripotent stem cells (iPSCs), into trophoblast, along the way making additional observations, further optimizing the protocol, but most importantly, defining the mechanisms underlying this process as it relates to early developmental events in the human embryo.

One of the first mechanistic reports, confirming the involvement of the BMP receptor machinery, was published by Chen et al., showing that hESC lacking phosphatidyl-inositol-glycan class A (PIG-A), required for the first step of glycosyl-phosphatidyl-inositol (GPI) synthesis, failed to induce trophoblast-associated genes, due to the lack of GPI-anchored BMP coreceptors (Chen et al. 2008). At about the same time, another group demonstrated that inhibition of activin/nodal signaling in hESC also induced the trophoblast lineage, although BMP signaling was still required for trophoblast differentiation in this context (Wu et al. 2008).

While the initial focus was on the STB lineage derived from these cells, some groups soon began to also note the expression of EVT markers, such as HLA-G, first documented by Das et al. (2007). Others compared BMP4-treated hESC against human mural TE, dissected from human embryos, finding significant overlap in gene expression: one described a 'trophectoderm core transcriptional regulatory circuitry' consisting of 13 transcription factors (including GATA2 and GATA3) that was recapitulated by the BMP4-treated hESC model (Bai et al. 2012); another study (Aghajanova et al. 2012) confirmed additional overlap between TE and BMP4treated hESC in genes coding for TE-secreted proteins, including leukemia inhibitory factor (LIF), PSGs, inhibin, follistatin, and WNT, many of which are known to be involved in embryo implantation (Giudice 1999, Aghajanova 2004). Both concluded that, based on the previously mentioned similarities in gene expression, BMP4-treated hESC is at least a viable model for studying human trophoblast differentiation.

Our group approached this model, asking the following question: if BMP4 induces terminally differentiated trophoblast lineages, including STB and EVT, does it do so through a developmentally correct program, that is, through a CTB progenitor phase? We answered this question by probing expression of TP63, a marker of epithelial stem cells which in the human placenta is uniquely expressed in CTB (Lee et al. 2007), in the context of BMP4-treated hESC. We found that TP63 is, in fact, induced prior to markers of more differentiated trophoblast and that its knockdown prevented terminal trophoblast differentiation downstream of BMP4 (Li et al. 2013). More recently, Krendl et al. identified steps involved in trophoblast lineage specification of hESC that are upstream of TP63, using a combination of transcriptome and epigenome profiling ( et al. 2017). They identified a combination of four transcription factors (GATA2, GATA3, TFAP2A, and TFAP2C), together called 'TEtra,' which are expressed in human TE and regulate suppression of pluripotency and induction of trophoblast lineage-specific genes downstream of BMP4 (Krendl et al. 2017).

Despite all the evidence, the BMP4-based model of human trophoblast differentiation has remained underutilized, most likely due to under-appreciation of the differences between mouse and human trophoblast, particularly during early gestation, as well as a lack of understanding of the role of BMP signaling in TE establishment and maintenance. Combined, these issues resulted in the conclusion that BMP4-treated hESC are, at best, extraembryonic mesoderm, not extraembryonic ectoderm (trophoblast) (Bernardo et al. 2011). But, in fact, this study used a suboptimal culture media for trophoblast differentiation of hESC, a media whose basal component was optimized for culture of mouse epiblast stem cells and not hESC (International Stem Cell Initiative Consortium 2010). While the authors correctly pointed out that CDX2 is not trophoblast-specific and, as such, its induction should not be used exclusively to evaluate trophoblast differentiation of pluripotent stem cells, they otherwise relied on mouse placental studies for identification of trophoblast-specific markers. In particular, they pointed to lack of induction of EOMES, a gene whose expression is completely lacking in both preimplantation human TE and early post-implantation human trophoblast (Blakeley et al. 2015, Soncin et al. 2018), to reject the trophoblast identity of BMP4-treated hESC. Finally, our gene expression profiling of human extraembryonic mesoderm (amnion and placental mesenchyme) and extraembryonic ectoderm/trophoblast (isolated primary CTB) has shown that BMP4-treated hESC cluster more closely with the latter (Li et al. 2013).

With respect to the role of BMP signaling in embryonic patterning, it is true that, prior to the initial report of BMP4-based trophoblast differentiation of hESC (Xu et al. 2002), BMP4 signaling had been mostly studied in the context of mesoderm induction (Zhao 2003). However, there have since been some clues that, in both mouse and human, this pathway is not exclusive to mesoderm induction: specifically, mouse embryos lacking Bmpr1a show not just lack of Brachyury/T (a gene required for early mesoderm differentiation) expression within the embryo-proper, but are also missing Eomes (a gene required for trophoblast stem cell maintenance in the mouse) expression from the extraembryonic ectoderm (Di-Gregorio et al. 2007). More recently, single-cell RNAseq of human blastocysts has confirmed expression of multiple components of the TGF $/ \mathrm{BMP}$ signaling pathway in this early stage of development, with several components (including SMAD1 and SMAD5) more highly expressed within human TE (Blakeley et al. 2015), indicating that, at the very least, these cells express the machinery required to respond to BMP signaling.

In fact, the balance of mesoderm and trophoblast differentiation downstream of BMP4 treatment of hESC has been documented in several studies. Yu et al. (2011) evaluated the role of FGF signaling, which, in the presence 
of BMP4, was found to sustain expression of NANOG, leading to induction of BRACHYURY/T, a mesoderm marker. Amita et al. (2013) used this information to establish more optimized conditions for trophoblast differentiation of hESC, applying a combination of BMP4, A83-01 (a TGF $\beta$ inhibitor), and PD173074 (an FGF receptor inhibitor). Termed 'BAP', this protocol inhibits mesoderm induction and accelerates trophoblast differentiation of hESC, compared to BMP4 alone, rapidly producing terminally differentiated STB and EVT (Amita et al. 2013). A more recent study has better delineated the mechanism of BMP4-mediated mesoderm vs trophoblast differentiation. Using both hESC and mouse epiblast stem cells (mEpiSCs), Kurek et al. (2015) showed that BMP4-mediated mesoderm induction, but not trophoblast induction, of these cells is WNT-dependent; thus, inhibitors of WNT signaling can be used to drive differentiation exclusively into the trophoblast lineage. We have used this information to establish an optimized protocol for BMP4-mediated trophoblast differentiation of pluripotent stem cells, using a combination of BMP4 and IWP2 to establish a pure population of CTB progenitor cells (Horii et al. 2019). Note that the need for WNT inhibition is specific to the transition from pluripotency to the trophoblast lineage; this is distinct from the need for WNT activation in the maintenance of the trophoblast stem cell state (see 'New models of human trophoblast differentiation: Human trophoblast stem cells').

As a model for normal human trophoblast differentiation, pluripotent stem cells (hPSCs) can be useful because they are widely available and, particularly, with the establishment of reprogramming methods for derivation of induced pluripotent stem cells (iPSC) from a variety of human somatic cells (Takahashi et al. 2007), a more widely acceptable system. Given the pluripotent state of the starting material, this model system allows for the study of not only just human trophoblast differentiation but also human trophoblast lineage specification. In fact, this model system has been used for this purpose, as described previously, establishing a role for the 'TEtra' factors (GATA2, GATA3, TFAP2A, and TFAP2C) in suppression of pluripotency and induction of the trophoblast lineage (Krendl et al. 2017). It has also been used to show that, similar to mouse, the TEA domain protein TEAD4 may be involved in human trophoblast lineage specification, by induction of GATA3 expression, downstream of BMP4 signaling (Home et al. 2012). In our own studies, we have developed a two-step protocol, which separates trophoblast lineage specification from terminal trophoblast differentiation (Horii et al. 2016, 2019). In the first step, we use a combination of BMP4 and IWP2 in a minimal basal media to derive formation of a pure population of EGFR ${ }^{+}$CTB progenitor cells (Horii et al. 2019). These cells are subsequently replated for terminal differentiation (into STB and EVT), using BMP4 in the setting of feeder-conditioned media (FCM) (Horii et al. 2016, 2019). We have used this system to show a possible role for VGLL1, a transcriptional co-factor, in the induction of TP63 and human trophoblast lineage specification (Soncin et al. 2018).

But perhaps the most compelling reason to use BMP4treated hPSCs is for modeling terminal trophoblast differentiation, particularly into EVT, but also into STB, in the setting of both normal development and placentabased pregnancy disorders, such as recurrent miscarriage, preeclampsia, and fetal growth restriction. Since CTB isolated from term placentae cannot differentiate into EVT (McMaster et al. 1995), the study of this lineage is limited to use of human trophoblast cell lines (i.e. HTR8-SVneo) or CTB isolated from first trimester human placental tissues. Since the latter are primarily sourced from elective terminations of pregnancy, their use may be limited due to both lack of knowledge about their disease potential (unknown pregnancy outcome) as well as local, state, or federal laws in some jurisdictions. We have shown that hPSC-derived CTB can be preferentially differentiated into $\mathrm{HLA}^{+} \mathrm{G}^{+}$, MMP2-secreting, invasive EVT using FCM+BMP4 under low oxygen tension (2\%) (Horii et al. 2016). We know that these cells reflect the same process in first trimester placenta, since both CTB derived from these tissues and hPSC-derived CTB differentiate into EVT under low oxygen tension in a HIF-dependent manner (Horii et al. 2016, Wakeland et al. 2017).

Our work has also established proof-of-concept for use of BMP4-treated hPSCs for modeling abnormal trophoblast differentiation. Using hPSCs which harbor an extra chromosome 21, we have shown that STB differentiation is compromised in this setting, similar to STB differentiation of primary CTB derived from Trisomy 21-involved placentae (Horii et al. 2016). Both primary and hPSC-derived CTB with Trisomy 21 showed defects in cell-cell fusion which could be rescued by activin treatment (Horii et al. 2016). Most recently, Sheridan et al. (2019) have established iPSCs from a cohort of normal and preeclamptic (PE) pregnancies and, using the 'BAP' protocol for trophoblast differentiation of these cells, have shown that PE-iPSC-derived trophoblast display a defect in invasion under high oxygen (20\%) tension. Although they have yet to characterize where the defect(s) occur(s) within the PE-iPSC-derived trophoblast, the fact that the phenotype of a complex pregnancy disorder can be recapitulated using this model system is extremely novel and exciting.

Nevertheless, hPSCs as a model for human trophoblast differentiation have several limitations. Most importantly, even though many human TE- and trophoblast-associated genes are induced in this system, BMP4-treated hPSCs do not fully resemble primary trophoblast based on marker expression (Aghajanova et al. 2012, Li et al. 2013). One glaring difference is the absent-to-low expression of ELF5, a transcription factor required for mouse trophoblast stem cell lineage specification and maintenance, which is also expressed 
at high levels in trophoblast of the early gestation human placenta (Hemberger et al. 2010). At least in mouse, Elf5 expression is regulated by promoter methylation, with high methylation levels (and hence absent expression) in mouse ESC and low levels (and hence expression of the gene) in mouse TSC (Ng et al. 2008). Human first trimester placental tissues also show hypomethylation of the ELF5 promoter, with ELF5 expressed in villous CTB (Hemberger et al. 2010). Human ESCs, on the other hand, show hypermethylation of the ELF5 promoter, even after treatment with BMP4 (Hemberger et al. 2010), although BMP4 treatment does decrease this methylation (Sarkar et al. 2015). Nevertheless, it is not clear whether, in this setting, this is a limitation of the BMP4-based model or whether this gene is simply not required for trophoblast lineage specification in human. The latter may be a possibility as, unlike mouse, ELF5 is not expressed in the TE of preimplantation human embryos (Blakeley et al. 2015), with its expression delayed until early post-implantation human trophoblast (Soncin et al. 2018). A second limitation is the continued expression of HLA class I antigens (Bernardo et al. 2011); however, it is noteworthy that the expression of these antigens does decrease following BMP4-induced trophoblast differentiation of pluripotent stem cells (Sarkar et al. 2015). Other limitations of the BMP4-based hPSC model include the as-yet undefined conditions for lineage-specific differentiation into EVT or STB and the lack of mature markers within either trophoblast subpopulation, indicating that further optimization of terminal trophoblast differentiation is necessary (Yabe et al. 2016, Horii et al. 2019). For this reason, comparison to primary cells continues to be required to improve and validate this system for further use.

\section{New models of human trophoblast differentiation: human trophoblast stem cells}

Over two decades ago, mouse trophoblast stem cells (mTSCs) were first derived from either preimplantation blastocyst-stage or extraembryonic ectoderm of early post-implantation embryos, using a combination of fibroblast growth factor-4 (FGF4) and media conditioned by mouse embryonic fibroblasts (MEF-CM) (Tanaka et al. 1998). Further studies showed that a combination of FGF4 and TGF $\beta$ /activin signaling contribute to the maintenance of these cells in their undifferentiated, stem-like state and that their removal leads to differentiation into both labyrinthine and spongiotrophoblast/trophoblast giant cell lineages, cells equivalent to human villous and extravillous trophoblast (Tanaka et al. 1998, Erlebacher et al. 2004, Soncin et al. 2015). Since this discovery, mTSCs have been used to study the role of multiple genes and signaling pathways important for trophoblast differentiation and placental development (Rossant 2001, Yagi et al. 2007, Senner \& Hemberger 2010,
Home et al. 2017). However, despite many attempts, the same conditions could not be applied to human embryos for derivation of analogous cells, likely due to differences in early developmental stages of mouse and human embryos (Niakan \& Eggan 2013, Kunath et al. 2014, Blakeley et al. 2015). Recently, Okae et al. (2018) applied knowledge of culture conditions for propagation and maintenance of epithelial stem cells to derive human trophoblast stem cells (hTSCs) from both blastocyst-stage human embryos and early first trimester placentae. These hTSCs use a combination of WNT activation and TGF $\beta$ inhibition to self-renew, and can be maintained in culture long-term, and be cryo-preserved for the later usage. They express numerous markers of early gestation trophoblast, including TEAD4, GATA3, TP63, as well as ELF5, and can differentiate into both STB and EVT (Okae et al. 2018).

While the derivation of these cells is a significant advance for the field of placental biology, several questions remain with respect to these cells. First, similar to primary cells from these tissue sources, these cells may remain of limited value due to the ethical and legal challenges against their use and their unknown disease potential. Second, while their profile (including expression of ITGA6) suggests that they originate from CTB, their exact location within the placenta remains unknown. The fact that they could not be derived from later gestation placental tissues may suggest the presence of a specific niche within the first trimester placenta; alternatively, it is possible that TSCs exist in later gestation but in significantly reduced numbers. Several groups have recently analyzed cellular heterogeneity within both the first trimester and term placentae using single-cell RNAseq (Pavličev et al. 2017, Tsang et al. 2017, Liu et al. 2018, Suryawanshi et al. 2018, Vento-Tormo et al. 2018). Analyses of these data, particularly comparing the CTB cell types at different gestational ages, may shed light on whether the TSC niche is, in fact, unique to early gestation and determine if this niche can be maintained later into pregnancy. Such a discovery could advance our understanding of placental regeneration, potentially laying the groundwork for targeting of this organ for regenerative therapy.

\section{New models of human trophoblast differentiation: 3D models of the human placenta}

While 2D culture is convenient and has been the standard for many years, 3D tissue culture offers conditions that are more physiologically relevant to the in vivo environment. Over the past few years, there have been rapid advances in 3D culture systems, with the development of miniature organs or 'organoids,' as well as establishment of 'organson-a-chip' (Huh et al. 2011). These advances have recently reached the human placenta field, with multiple groups establishing such model systems.

Specifically, two groups have generated selfreplicating trophoblast organoids from first trimester 
placental tissues (Haider et al. 2018, Turco et al. 2018). Both groups used media with similar composition to that used for hTSCs (Okae et al. 2018), resulting in organoids which hold similar structures, with an outer CTB layer and inner group of STB (Haider et al. 2018, Turco et al. 2018). There were slight differences in passaging and choice of differentiation media. Specifically, Turco et al. chose an EVT differentiation media which is most similar to that used by Okae et al. (2018), containing neuregulin-1 (NRG1) as the initiating factor (Turco et al. 2018); at the same time, Haider et al. showed that removal of WNT activators (R-spondin and CHIR99021) from their organoid media was sufficient to initiate differentiation into $\mathrm{NOTCH}_{1}{ }^{+} \mathrm{EVT}$ precursors, while WNT signaling was required for further differentiation of EVT (Haider et al. 2018). Similar to hTSCs, trophoblast organoids have only been derived from first trimester placental tissues, again rendering these models of potential limited value due to the ethical and legal challenges to their use and their unknown disease potential, thus necessitating further studies for establishment of similar organoids from later gestation tissues. Another potential limitation of these organoids is that their morphology contrasts with that of chorionic villi, with CTB comprising the outer layer and STB being confined to the inner compartment (Haider et al. 2018, Turco et al. 2018). This results in the presence of a mixed group of trophoblast in culture, which may confound data analysis; at the same time, the simultaneous presence of different lineages may allow (through cross-talk) better maintenance and/or differentiation of the distinct cell types. In addition, differentiation of the outer CTB into EVT may better recapitulate the trophoblast cell column, allowing the study of progressive differentiation of cells into this lineage (Haider et al. 2018).

Aside from organoids, several other methods of 3D culture have recently been developed to study trophoblast function, mostly in context of the chorionic villus, the main exchange interface of the human placenta. McConkey et al. (2016) used the rotating wall vessel bioreactor to culture JEG3 attached to Cytodex beads, resulting in the formation of multinucleated (STB-like) cells which, similar to primary term STB, were resistant to infection by viruses as well as Toxoplasma gondii. More recently, multiple groups have developed 'placenta-on-a-chip' models of chorionic villus in order to mimic the transport functions of the placenta in vitro (Blundell et al. 2016, Arumugasaamy et al. 2018, Nishiguchi et al. 2019). These models offer an advantage over both 2D models and 3D organoid culture, providing a platform for studying transport of drugs, nutrients, and pathogens across the vasculosyncytial barrier. They can also be modified to model the barrier at different gestational ages and manipulated, both genetically and environmentally, to reproduce diseaselike conditions. However, most of these studies so far have used BeWo (choriocarcinoma-derived) cells for modeling the trophoblast barrier, with only one group
(Nishiguchi et al. 2019) using primary CTB. Nevertheless, these novel technologies provide a platform for studying transport across the villus barrier, a process which is otherwise difficult to study, relying mostly on ex vivo perfusion of human placenta after delivery. Development of these novel 3D systems will allow the study of cell-cell communications and their effect on placental function, significantly advancing our understanding of structurefunction relationships within this organ.

\section{Conclusions and future perspectives}

The human placenta is a difficult organ to study, in part, due to lack of a proper model system for its main functional epithelial component, the trophoblast. This review has focused on describing advances in regenerative medicine-based technologies, including derivation of human embryonic and, more recently, trophoblast stem cells, from blastocyst-stage human embryos (Fig. 1A), derivation of trophoblast stem cells and trophoblast organoids from early gestation human placenta (Fig. 1B), and derivation of induced pluripotent stem cells and establishment of methods for their differentiation toward the trophoblast lineage (Fig. 1C). We will now touch on some of the most important possible next steps.

One of the most exciting advances discussed in this review is the ability to reprogram cells of a placenta at delivery, for which the pregnancy outcome is known, generating iPSCs which can then be differentiated into trophoblast (Fig. 1C). Currently, this has only been done with mesenchymal stem cells (MSCs) from normal and preeclamptic placentae, with trophoblast differentiation of the resulting iPSCs showing phenotypic abnormalities that correlate with this placental dysfunction (Sheridan et al. 2019). However, much work remains to be done, including more optimal differentiation of iPSCs into trophoblast and establishment of iPSC for modeling other placental disorders. One possibility is to use the media and culture techniques recently developed for hTSC and trophoblast organoids and apply them to iPSC-derived CTB in order to establish iPSC-derived 'TSC' (Fig. 1C). One group claims to have applied the Okae et al. (2018) media to hESC-derived trophoblast with resulting cells which resemble primary hTSC based on their transcriptome (Mischler et al. 2019). Another more recent publication first converts hESC/iPSC first into a 'naive' state of pluripotency, then applies the media established by Okae et al. (2018) to derive TSClike cells (Dong et al. 2020). However, what is not clear is whether this latter method would preserve the disease-specific epigenetic marks on iPSC. Additional studies, particularly comparison of TSC derived from both naive vs primed $\mathrm{hESC} / \mathrm{iPSC}$, are needed to address this question.

Perhaps a more optimal method for derivation of disease-specific iPSC would be to start by using primary term CTB, instead of MSCs, from diseased placentae, 

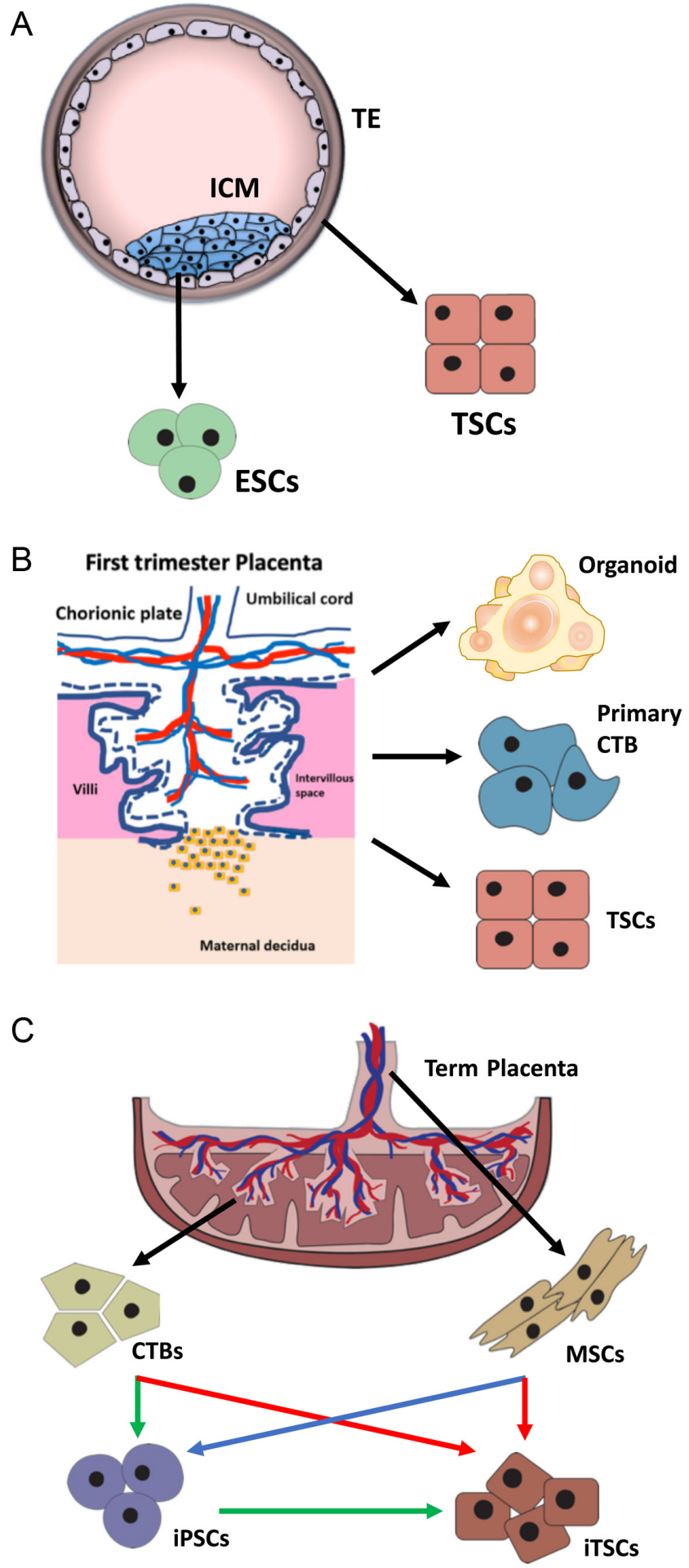

Figure 1 (A) An illustration of a blastocyst-stage human embryo. Both human embryonic stem cells (ESC) and trophoblast stem cells (TSC) have now been established, derived from the inner cell mass (ICM) and trophectoderm (TE) of human embryos. (B) An illustration of early gestation (first trimester) human placenta. While primary cytotrophoblast (CTB) derived from this tissue have been the gold standard in studies of human trophoblast differentiation for many years, recent studies have established protocols for derivation of potentially leading to an epigenetic state in the resulting iPSC-derived TSC that is more representative of the cellof-origin (trophoblast) that we aim to study (Fig. 1C). Finally, another exciting possibility would be to apply our knowledge of transcription factors that induce human trophoblast lineage and hTSC maintenance to CTB and/or MSC and reprogram these cells directly into TSC (i.e. generate 'induced trophoblast stem cells' or iTSCs, Fig. 1C), rather than going through a pluripotent intermediate. This has already been done in mouse, generating iTSC that mimic primary, blastocyst-derived TSC (Benchetrit et al. 2015, Kubaczka et al. 2015).

Just as the Okae media have been applied to hESC/iPSC, so can the culture methods for derivation of trophoblast organoids. Since hESC/iPSC can also be genetically manipulated, the role of specific genes can be tested in both maintenance and differentiation of TSC derived from these cells. In addition, both primary and hESC/iPSC-derived hTSC can theoretically be combined with organ-on-achip technologies, in order to model the vasculosyncytial barrier with both normal and abnormal trophoblast. This, combined with the ability to genetically manipulate the component cell types, will allow for modeling of the human placenta, not just during normal development but also in numerous pregnancy-associated disorders, establishing models that can be used for identification of both diagnostic markers and therapeutic targets.

The development of the previously mentioned technologies hasallowed for establishment of significantly more advanced models of human trophoblast. However, much work still remains, particularly in the actual application of these systems for better understanding human placental function and modeling placenta-based pregnancy complications.

trophoblast stem cells (TSC) and trophoblast organoids, which can self-replicate and be further differentiated into both

syncytiotrophoblast and extravillous trophoblast. Utility of both embryo- and first trimester placenta-derived cells is limited by ethical issues as well as their unknown disease potential. (C) An illustration of human placenta at delivery. Current reprogramming technologies enable us to generate induced pluripotent stem cells (iPSCs) starting with somatic cell types, including placental cells at delivery. This has been done mostly using mesenchymal stem cells (MSCs) derived from the umbilical cord, but can also potentially be done using cytotrophoblast (CTB) as starting material. iPSCs (as well as ESC) can be differentiated into trophoblast using various protocols. Application of TSC/organoid culture media to iPSC/ESC-derived trophoblast has the potential to generate TSC-like cells. At the same time, TSCspecific transcription/reprogramming factors could potentially be used to generate 'induced trophoblast stem cells' (iTSC), directly from MSCs or CTBs. This model system is potentially powerful, because it will be applicable not only to normal pregnancies but also to pregnancies associated with placenta-based dysfunction. Note that the blue arrow indicates a method which has already been established and applied, the green arrow represents technology that is available but has yet to be applied, and the red arrow points to protocol(s) that have yet to be developed. 


\section{Declaration of interest}

The authors declare that there is no conflict of interest that could be perceived as prejudicing the impartiality of the research reported.

\section{Funding}

This work was supported by funds from NIH/NICHD (R01-HD089537 to M M P and K99-HD091452 to M H). O T was supported by the Bridges to Stem Cell Research Internship Program Grant from the California Institute for Regenerative Medicine (CIRM EDUC2-08376).

Acknowledgements This work was partially presented by Dr Parast at the Gordon Research Conference on Mammalian Reproduction in July 2018, in Lucca, Italy.

\section{Author contribution statement}

$\mathrm{M} \mathrm{H}$ and M M P wrote the manuscript text. O T prepared the first draft of figures. T B assisted with the final version of both the manuscript and figures.

\section{References}

Aghajanova L 2004 Leukemia inhibitory factor and human embryo implantation. Annals of the New York Academy of Sciences 1034 176-183. (https://doi.org/10.1196/annals.1335.020)

Aghajanova L, Shen S, Rojas AM, Fisher SJ, Irwin JC \& Giudice LC 2012 Comparative transcriptome analysis of human trophectoderm and embryonic stem cell-derived trophoblasts reveal key participants in early implantation. Biology of Reproduction 86 1-21. (https://doi.org/10.1095/ biolreprod.111.092775)

Amita M, Adachi K, Alexenko AP, Sinha S, Schust DJ, Schulz LC, Roberts RM \& Ezashi T 2013 Complete and unidirectional conversion of human embryonic stem cells to trophoblast by BMP4. PNAS 110 E1212E1221. (https://doi.org/10.1073/pnas.1303094110)

Apps R, Murphy SP, Fernando R, Gardner L, Ahad T \& Moffett A 2009 Human leucocyte antigen (HLA) expression of primary trophoblast cells and placental cell lines, determined using single antigen beads to characterize allotype specificities of anti-HLA antibodies. Immunology 127 26-39. (https://doi.org/10.1111/j.1365-2567.2008.03019.x)

Arumugasaamy N, Ettehadieh LE, Kuo CY, Paquin-Proulx D, Kitchen SM, Santoro M, Placone JK, Silveira PP, Aguiar RS, Nixon DF et al. 2018 Biomimetic placenta-fetus model demonstrating maternal-fetal transmission and fetal neural toxicity of zika virus. Annals of Biomedical Engineering 46 1963-1974. (https://doi.org/10.1007/s10439-018-2090-y)

Baczyk D, Dunk C, Huppertz B, Maxwell C, Reister F, Giannoulias D \& Kingdom JC 2006 Bi-potential behaviour of cytotrophoblasts in first trimester chorionic villi. Placenta 27 367-374. (https://doi.org/10.1016/j. placenta.2005.03.006)

Bai Q, Assou S, Haouzi D, Ramirez JM, Monzo C, Becker F, GerbalChaloin S, Hamamah S, De Vos J 2012 Dissecting the first transcriptional divergence during human embryonic development. Stem Cell Reviews and Reports 8 150-162. (https://doi.org/10.1007/s12015-011-9301-3)

Benchetrit H, Herman S, van Wietmarschen N, Wu T, Makedonski K, Maoz N, Yom Tov N, Stave D, Lasry R, Zayat V et al. 2015 Extensive nuclear reprogramming underlies lineage conversion into functional trophoblast stem-like cells. Cell Stem Cell 17 543-556. (https://doi. org/10.1016/j.stem.2015.08.006)

Benirschke K, Burton GJ \& Baergen RN 2012 Pathology of the Human Placenta, 6th ed. Heidelberg, Germany: Springer.

Bernardo AS, Faial T, Gardner L, Niakan KK, Ortmann D, Senner CE, Callery EM, Trotter MW, Hemberger M, Smith JC et al. 2011 BRACHYURY and CDX2 mediate BMP-induced differentiation of human and mouse pluripotent stem cells into embryonic and extraembryonic lineages. Cell Stem Cell 9 144-155. (https://doi.org/10.1016/j.stem.2011.06.015)

Bilban M, Tauber S, Haslinger P, Pollheimer J, Saleh L, Pehamberger H, Wagner O \& Knöfler M 2010 Trophoblast invasion: assessment of cellular models using gene expression signatures. Placenta 31 989-996. (https://doi.org/10.1016/j.placenta.2010.08.011)

Bischof P \& Irminger-Finger I 2005 The human cytotrophoblastic cell, a mononuclear chameleon. International Journal of Biochemistry and Cell Biology 37 1-16. (https://doi.org/10.1016/j.biocel.2004.05.014)

Blakeley P, Fogarty NM, del Valle I, Wamaitha SE, Hu TX, Elder K, Snell P, Christie L, Robson P \& Niakan KK 2015 Defining the three cell lineages of the human blastocyst by single-cell RNA-seq. Development $\mathbf{1 4 2}$ 3151-3165. (https://doi.org/10.1242/dev.123547)

Blundell C, Tess ER, Schanzer AS, Coutifaris C, Su EJ, Parry S \& Huh D 2016 A microphysiological model of the human placental barrier. Lab on a Chip 16 3065-3073. (https://doi.org/10.1039/C6LC00259E)

Boyd J \& Hamilton W 1970 The Human Placenta. Cambridge: W. Heffer \& Sons Ltd.

Caniggia I, Mostachfi H, Winter J, Gassmann M, Lye SJ, Kuliszewski M \& Post M 2000 Hypoxia-inducible factor-1 mediates the biological effects of oxygen on human trophoblast differentiation through TGFbeta. Journal of Clinical Investigation 105 577-587. (https://doi.org/10.1172/JCl8316)

Cerneus DP \& van der Ende A 1991 Apical and basolateral transferrin receptors in polarized BeWo cells recycle through separate endosomes. Journal of Cell Biology 114 1149-1158. (https://doi.org/10.1083/ jcb.114.6.1149)

Chen B, Nelson DM \& Sadovsky Y 2006 N-myc down-regulated gene 1 modulates the response of term human trophoblasts to hypoxic injury. Journal of Biological Chemistry 281 2764-2772. (https://doi.org/10.1074/ jbc.M507330200)

Chen G, Ye Z, Yu X, Zou J, Mali P, Brodsky RA \& Cheng L 2008 Trophoblast differentiation defect in human embryonic stem cells lacking PIG-A and GPI-anchored cell-surface proteins. Cell Stem Cell 2 345-355. (https:// doi.org/10.1016/j.stem.2008.02.004)

Das P, Ezashi T, Schulz LC, Westfall SD, Livingston KA \& Roberts RM 2007 Effects of fgf2 and oxygen in the bmp4-driven differentiation of trophoblast from human embryonic stem cells. Stem Cell Research 1 61-74. (https://doi.org/10.1016/j.scr.2007.09.004)

Deglincerti A, Croft GF, Pietila LN, Zernicka-Goetz M, Siggia ED \& Brivanlou AH 2016 Self-organization of the in vitro attached human embryo. Nature 533 251-254. (https://doi.org/10.1038/nature17948)

De Paepe C, Cauffman G, Verloes A, Sterckx J, Devroey P, Tournaye H, Liebaers I \& Van de Velde H 2013 Human trophectoderm cells are not yet committed. Human Reproduction 28 740-749. (https://doi. org/10.1093/humrep/des432)

Di-Gregorio A, Sancho M, Stuckey DW, Crompton LA, Godwin J, Mishina Y \& Rodriguez TA 2007 BMP signalling inhibits premature neural differentiation in the mouse embryo. Development 134 3359-3369. (https://doi.org/10.1242/dev.005967)

Dong C, Beltcheva M, Gontarz P, Zhang B, Popli P, Fischer LA, Khan SA, Park KM, Yoon EJ, Xing X et al. 2020 Derivation of trophoblast stem cells from naïve human pluripotent stem cells. elife 9 e52504. (https://doi. org/10.7554/eLife.52504)

Donnison M, Beaton A, Davey HW, Broadhurst R, L'Huillier P \& Pfeffer PL 2005 Loss of the extraembryonic ectoderm in Elf5 mutants leads to defects in embryonic patterning. Development 132 2299-2308. (https:// doi.org/10.1242/dev.01819)

Erlebacher A, Price KA \& Glimcher LH 2004 Maintenance of mouse trophoblast stem cell proliferation by TGF-beta/activin. Developmental Biology 275 158-169. (https://doi.org/10.1016/j.ydbio.2004.07.032)

Fisher SJ, Cui TY, Zhang L, Hartman L, Grahl K, Zhang GY, Tarpey J \& Damsky CH 1989 Adhesive and degradative properties of human placental cytotrophoblast cells in vitro. Journal of Cell Biology 109 891-902. (https://doi.org/10.1083/jcb.109.2.891)

Fitzgerald W, Gomez-Lopez N, Erez O, Romero R \& Margolis L 2018 Extracellular vesicles generated by placental tissues ex vivo: a transport system for immune mediators and growth factors. American Journal of Reproductive Immunology 80 e12860. (https://doi.org/10.1111/aji.12860)

Fogarty NME, McCarthy A, Snijders KE, Powell BE, Kubikova N, Blakeley P, Lea R, Elder K, Wamaitha SE, Kim D et al. 2017 Genome editing reveals a role for OCT4 in human embryogenesis. Nature $\mathbf{5 5 0}$ 67-73. (https:// doi.org/10.1038/nature24033) 
Gerami-Naini B, Dovzhenko OV, Durning M, Wegner FH, Thomson JA \& Golos TG 2004 Trophoblast differentiation in embryoid bodies derived from human embryonic stem cells. Endocrinology 145 1517-1524. (https://doi.org/10.1210/en.2003-1241)

Giudice LC 1999 Potential biochemical markers of uterine receptivity. Human Reproduction 14 (Supplement 2) 3-16. (https://doi.org/10.1093/ humrep/14.suppl_2.3)

Graham CH, Hawley TS, Hawley RG, MacDougall JR, Kerbel RS, Khoo N \& Lala PK 1993 Establishment and characterization of first trimester human trophoblast cells with extended lifespan. Experimental Cell Research 206 204-211. (https://doi.org/10.1006/excr.1993.1139)

Haider S, Meinhardt G, Saleh L, Kunihs V, Gamperl M, Kaindl U, Ellinger A, Burkard TR, Fiala C, Pollheimer J et al. 2018 Self-renewing trophoblast organoids recapitulate the developmental program of the early human placenta. Stem Cell Reports 11 537-551. (https://doi.org/10.1016/j. stemcr.2018.07.004)

Hemberger M, Udayashankar R, Tesar P, Moore H \& Burton GJ 2010 ELF5enforced transcriptional networks define an epigenetically regulated trophoblast stem cell compartment in the human placenta. Human Molecular Genetics 19 2456-2467. (https://doi.org/10.1093/hmg/ ddq128)

Hertig AT, Rock J, Adams EC \& Mulligan WJ 1954 On the preimplantation stages of the human ovum: a description of four normal and four abnormal specimens ranging from the second to the fifth day of development. Contributions to Embryology of the Carnegie Institution 35 119-220.

Hertig AT, Rock J \& Adams EC 1956 A description of 34 human ova within the first 17 days of development. American Journal of Anatomy $\mathbf{9 8}$ 435-493. (https://doi.org/10.1002/aja.1000980306)

Home P, Saha B, Ray S, Dutta D, Gunewardena S, Yoo B, Pal A, Vivian JL, Larson M, Petroff M et al. 2012 Altered subcellular localization of transcription factor TEAD4 regulates first mammalian cell lineage commitment. PNAS 109 7362-7367. (https://doi.org/10.1073/ pnas.1201595109)

Home P, Kumar RP, Ganguly A, Saha B, Milano-Foster J, Bhattacharya B, Ray S, Gunewardena S, Paul A, Camper SA et al. 2017 Genetic redundancy of GATA factors in the extraembryonic trophoblast lineage ensures the progression of preimplantation and postimplantation mammalian development. Development 144 876-888. (https://doi. org/10.1242/dev.145318)

Horii M, Li Y, Wakeland AK, Pizzo DP, Nelson KK, Sabatini K, Laurent LC, Liu Y \& Parast MM 2016 Human pluripotent stem cells as a model of trophoblast differentiation in both normal development and disease. PNAS 113 E3882-E3891. (https://doi.org/10.1073/pnas.1604747113)

Horii M, Bui T, Touma O, Cho HY \& Parast MM 2019 An improved two-step protocol for trophoblast differentiation of human pluripotent stem cells. Current Protocols in Stem Cell Biology $\mathbf{5 0}$ e96. (https://doi. org/10.1002/cpsc.96)

Huh D, Hamilton GA \& Ingber DE 2011 From three-dimensional cell culture to organs-on-chips. Trends in Cell Biology 21 745-754. (https:// doi.org/10.1016/j.tcb.2011.09.005)

International Stem Cell Initiative Consortium, Akopian V, Andrews PW, Beil S, Benvenisty N, Brehm J, Christie M, Ford A, Fox V, Gokhale PJ et al. 2010 Comparison of defined culture systems for feeder cell free propagation of human embryonic stem cells. In Vitro Cellular and Developmental Biology: Animal 46 247-258. (https://doi.org/10.1007/ s11626-010-9297-z)

James JL, Carter AM \& Chamley LW 2012 Human placentation from nidation to 5 weeks of gestation. Part I: what do we know about formative placental development following implantation? Placenta 33 327-334 (https://doi.org/10.1016/j.placenta.2012.01.020)

Jauniaux E, Poston L \& Burton GJ 2006 Placental-related diseases of pregnancy: involvement of oxidative stress and implications in human evolution. Human Reproduction Update 12 747-755. (https://doi. org/10.1093/humupd/dml016)

Kliman HJ, Nestler JE, Sermasi E, Sanger JM \& Strauss 3rd JF 1986 Purification, characterization, and in vitro differentiation of cytotrophoblasts from human term placentae. Endocrinology 118 1567-1582. (https://doi.org/10.1210/endo-118-4-1567)

Knöfler M \& Pollheimer J 2013 Human placental trophoblast invasion and differentiation: a particular focus on Wnt signaling. Frontiers in Genetics 4 190. (https://doi.org/10.3389/fgene.2013.00190)
Krendl C, Shaposhnikov D, Rishko V, Ori C, Ziegenhain C, Sass S, Simon L, Müller NS, Straub T, Brooks KE et al. 2017 GATA2/3TFAP2A/C transcription factor network couples human pluripotent stem cell differentiation to trophectoderm with repression of pluripotency. PNAS 114 E9579-E9588. (https;//doi.org/10.1073/pnas.1708341114)

Kubaczka C, Senner CE, Cierlitza M, Araúzo-Bravo MJ, Kuckenberg P, Peitz M, Hemberger M \& Schorle H 2015 Direct induction of trophoblast stem cells from murine fibroblasts. Cell Stem Cell 17 557-568. (https:// doi.org/10.1016/j.stem.2015.08.005)

Kunath T, Yamanaka Y, Detmar J, MacPhee D, Caniggia I, Rossant J \& Jurisicova A 2014 Developmental differences in the expression of FGF receptors between human and mouse embryos. Placenta 35 1079-1088. (https://doi.org/10.1016/j.placenta.2014.09.008)

Kurek D, Neagu A, Tastemel M, Tüysüz N, Lehmann J, van de Werken HJG, Philipsen S, van der Linden R, Maas A, van IJcken WFJ et al. 2015 Endogenous WNT signals mediate BMP-induced and spontaneous differentiation of epiblast stem cells and human embryonic stem cells. Stem Cell Reports 4 114-128. (https;//doi.org/10.1016/j. stemcr.2014.11.007)

Lee Y, Kim KR, McKeon F, Yang A, Boyd TK, Crum CP \& Parast MM 2007 A unifying concept of trophoblastic differentiation and malignancy defined by biomarker expression. Human Pathology 38 1003-1013. (https://doi. org/10.1016/j.humpath.2006.12.012)

Li Y, Moretto-Zita M, Soncin F, Wakeland A, Wolfe L, Leon-Garcia S, Pandian R, Pizzo D, Cui L, Nazor K et al. 2013 BMP4-directed trophoblast differentiation of human embryonic stem cells is mediated through a $\Delta \mathrm{Np} 63+$ cytotrophoblast stem cell state. Development 140 3965-3976. (https://doi.org/10.1242/dev.092155)

Lindenberg S, Hyttel P, Sjøgren A \& Greve T 1989 A comparative study of attachment of human, bovine and mouse blastocysts to uterine epithelial monolayer. Human Reproduction 4 446-456. (https://doi.org/10.1093/ oxfordjournals.humrep.a136925)

Liu Y, Fan X, Wang R, Lu X, Dang YL, Wang H, Lin HY, Zhu C, Ge H, Cross JC et al. 2018 Single-cell RNA-seq reveals the diversity of trophoblast subtypes and patterns of differentiation in the human placenta. Cell Research 28 819-832. (https://doi.org/10.1038/s41422018-0066-y)

McConkey CA, Delorme-Axford E, Nickerson CA, Kim KS, Sadovsky Y, Boyle JP \& Coyne CB 2016 A three-dimensional culture system recapitulates placental syncytiotrophoblast development and microbial resistance. Science Advances 2 e1501462. (https://doi.org/10.1126/ sciadv.1501462)

McMaster MT, Librach CL, Zhou Y, Lim KH, Janatpour MJ, DeMars R, Kovats S, Damsky C \& Fisher SJ 1995 Human placental HLA-G expression is restricted to differentiated cytotrophoblasts. Journal of Immunology 154 3771-3778.

Mischler A, Karakis V, Mahinthakumar J, Carberry C, San Miguel A, Rager J, Fry R \& Rao BM 2019 Two distinct trophectoderm lineage stem cells from human pluripotent stem cells. BioRxiv 2019. (https://doi. org/10.1101/762542)

Miller RK, Genbacev O, Turner MA, Aplin JD, Caniggia I \& Huppertz B 2005 Human placental explants in culture: approaches and assessments. Placenta 26 439-448. (https://doi.org/10.1016/j.placenta.2004.10.002)

Niakan KK \& Eggan K 2013 Analysis of human embryos from zygote to blastocyst reveals distinct gene expression patterns relative to the mouse. Developmental Biology 375 54-64. (https://doi.org/10.1016/j. ydbio.2012.12.008)

Niakan KK, Han J, Pedersen RA, Simon C \& Pera RA 2012 Human preimplantation embryo development. Development 139 829-841. (https:// doi.org/10.1242/dev.060426)

Nishiguchi A, Gilmore C, Sood A, Matsusaki M, Collett G, Tannetta D, Sargent IL, McGarvey J, Halemani ND, Hanley J et al. 2019 In vitro placenta barrier model using primary human trophoblasts, underlying connective tissue and vascular endothelium. Biomaterials 192 140-148. (https://doi.org/10.1016/j.biomaterials.2018.08.025)

Nishioka N, Inoue K, Adachi K, Kiyonari H, Ota M, Ralston A, Yabuta N, Hirahara S, Stephenson RO, Ogonuki N et al. 2009 The Hippo signaling pathway components Lats and Yap pattern Tead4 activity to distinguish mouse trophectoderm from inner cell mass. Developmental Cell $\mathbf{1 6}$ 398-410. (https://doi.org/10.1016/j.devcel.2009.02.003)

Ng RK, Dean W, Dawson C, Lucifero D, Madeja Z, Reik W \& Hemberger M 2008 Epigenetic restriction of embryonic cell lineage fate by methylation 
of Elf5. Nature Cell Biology 10 1280-1290. (https://doi.org/10.1038/ ncb1786)

Norwitz ER 2006 Defective implantation and placentation: laying the blueprint for pregnancy complications. Reproductive BioMedicine Online 13 591-599. (https://doi.org/10.1016/S1472-6483(10)60649-9)

Okae H, Toh H, Sato T, Hiura H, Takahashi S, Shirane K, Kabayama Y, Suyama M, Sasaki H \& Arima T 2018 Derivation of human trophoblast stem cells. Cell Stem Cell 22 50.e6-63.e6. (https://doi.org/10.1016/j. stem.2017.11.004)

Pavličev M, Wagner GP, Chavan AR, Owens K, Maziarz J, Dunn-Fletcher C, Kallapur SG, Muglia L \& Jones H 2017 Single-cell transcriptomics of the human placenta: inferring the cell communication network of the maternal-fetal interface. Genome Research 27 349-361. (https;//doi. org/10.1101/gr.207597.116)

Petropoulos S, Edsgard D, Reinius B, Deng Q, Panula SP, Codeluppi S, Reyes AP, Linnarsson S, Sandberg R \& Lanner F 2016 Single-cel RNAseq reveals lineage and $X$ chromosome dynamics in human preimplantation embryos. Cell $\mathbf{1 6 5}$ 1012-1026. (https://doi org/10.1016/j.cell.2016.03.023)

Romero R, Kusanovic JP, Chaiworapongsa T \& Hassan SS 2011 Placental bed disorders in preterm labor, preterm PROM, spontaneous abortion and abruptio placentae. Best Practice and Research: Clinical Obstetrics and Gynaecology 25 313-327 (https://doi.org/10.1016/j. bpobgyn.2011.02.006)

Rossant J 2001 Stem cells from the Mammalian blastocyst. Stem Cells 19 477-482. (https://doi.org/10.1634/stemcells.19-6-477)

Russ AP, Wattler S, Colledge WH, Aparicio SA, Carlton MB, Pearce JJ, Barton SC, Surani MA, Ryan K, Nehls MC et al. 2000 Eomesodermin is required for mouse trophoblast development and mesoderm formation. Nature 404 95-99. (https://doi.org/10.1038/35003601)

Sarkar P, Randall SM, Collier TS, Nero A, Russell TA, Muddiman DC \& Rao BM 2015 Activin/Nodal signaling switches the terminal fate of human embryonic stem cell-derived trophoblasts. Journal of Biological Chemistry 290 8834-8848. (https://doi.org/10.1074/jbc.M114.620641)

Senner CE \& Hemberger M 2010 Regulation of early trophoblast differentiation - lessons from the mouse. Placenta 31 944-950. (https:// doi.org/10.1016/j.placenta.2010.07.013)

Shahbazi MN, Jedrusik A, Vuoristo S, Recher G, Hupalowska A, Bolton V, Fogarty NNM, Campbell A, Devito L, Ilic D et al. 2016 Self-organization of the human embryo in the absence of maternal tissues. Nature Cell Biology 18 700-708. (https://doi.org/10.1038/ncb3347)

Sheridan MA, Yang Y, Jain A, Lyons AS, Yang P, Brahmasani SR, Dai A, Tian Y, Ellersieck MR, Tuteja G et al. 2019 Early onset preeclampsia in model for human placental trophoblast. PNAS 116 4336-4345. (https:// doi.org/10.1073/pnas.1816150116)

Soncin F, Natale D \& Parast MM 2015 Signaling pathways in mouse and human trophoblast differentiation: a comparative review. Cellular and Molecular Life Sciences 72 1291-1302. (https://doi.org/10.1007/s00018014-1794-x)

Soncin F, Khater M, To C, Pizzo D, Farah O, Wakeland A, Arul Nambi Rajan K, Nelson KK, Chang CW, Moretto-Zita M et al. 2018 Comparative analysis of mouse and human placentae across gestation reveals species-specific regulators of placental development. Development 145 dev156273. (https://doi.org/10.1242/dev.156273)

Straszewski-Chavez SL, Abrahams VM, Alvero AB, Aldo PB, Ma Y, Guller S, Romero R \& Mor G 2009 The isolation and characterization of a nove telomerase immortalized first trimester trophoblast cell line, Swan 71 Placenta 30 939-948. (https://doi.org/10.1016/j.placenta.2009.08.007)

Strumpf D, Mao CA, Yamanaka Y, Ralston A, Chawengsaksophak K, Beck F \& Rossant J $2005 \mathrm{Cdx} 2$ is required for correct cell fate specification and differentiation of trophectoderm in the mouse blastocyst. Development 132 2093-2102. (https://doi.org/10.1242/dev.01801)

Suryawanshi H, Morozov P, Straus A, Sahasrabudhe N, Max KEA Garzia A, Kustagi M, Tuschl T \& Williams Z 2018 A single-cell survey of the human first-trimester placenta and decidua. Science Advances 4 eaau4788. (https://doi.org/10.1126/sciadv.aau4788)

Takahashi K, Tanabe K, Ohnuki M, Narita M, Ichisaka T, Tomoda K \& Yamanaka S 2007 Induction of pluripotent stem cells from adult human fibroblasts by defined factors. Cell 131 861-872. (https://doi. org/10.1016/j.cell.2007.11.019)

Tanaka S, Kunath T, Hadjantonakis AK, Nagy A \& Rossant J 1998 Promotion of trophoblast stem cell proliferation by FGF4. Science 282 2072-2075. (https://doi.org/10.1126/science.282.5396.2072)

Thomson JA, Itskovitz-Eldor J, Shapiro SS, Waknitz MA, Swiergiel JJ, Marshall VS \& Jones JM 1998 Embryonic stem cell lines derived from human blastocysts. Science 282 1145-1147. (https://doi.org/10.1126/ science.282.5391.1145)

Tong M \& Chamley LW 2018 Isolation and characterization of extracellular vesicles from ex vivo cultured human placental explants. Methods in Molecular Biology 1710 117-129. (https;//doi.org/10.1007/978-1-49397498-6_9)

Tsang JCH, Vong JSL, Ji L, Poon LCY, Jiang P, Lui KO, Ni YB, To KF, Cheng YKY, Chiu RWK et al. 2017 Integrative single-cell and cell-free plasma RNA transcriptomics elucidates placental cellular dynamics. PNAS 114 E7786-E7795. (https://doi.org/10.1073/pnas.1710470114)

Turco MY, Gardner L, Kay RG, Hamilton RS, Prater M, Hollinshead MS, McWhinnie A, Esposito L, Fernando R, Skelton H et al. 2018 Trophoblast organoids as a model for maternal-fetal interactions during human placentation. Nature 564 263-267. (https://doi.org/10.1038/s41586018-0753-3)

Vento-Tormo R, Efremova $M$, Botting RA, Turco MY, Vento-Tormo $M$, Meyer KB, Park JE, Stephenson E, Polański K, Goncalves A et al. 2018 Single-cell reconstruction of the early maternal-fetal interface in humans. Nature 563 347-353. (https://doi.org/10.1038/s41586-018-0698-6)

Wakeland AK, Soncin F, Moretto-Zita M, Chang CW, Horii M, Pizzo D, Nelson KK, Laurent LC \& Parast MM 2017 Hypoxia directs human extravillous trophoblast differentiation in a hypoxia-inducible factordependent manner. American Journal of Pathology 187 767-780. (https://doi.org/10.1016/j.ajpath.2016.11.018)

Wu Z, Zhang W, Chen G, Cheng L, Liao J, Jia N, Gao Y, Dai H, Yuan J, Cheng L et al. 2008 Combinatorial signals of activin/nodal and bone morphogenic protein regulate the early lineage segregation of human embryonic stem cells. Journal of Biological Chemistry 283 24991-5002. (https://doi.org/10.1074/jbc.M803893200)

Xu RH, Chen X, Li DS, Li R, Addicks GC, Glennon C, Zwaka TP \& Thomson JA 2002 BMP4 initiates human embryonic stem cell differentiation to trophoblast. Nature Biotechnology 20 1261-1264. (https://doi.org/10.1038/nbt761)

Yabe S, Alexenko AP, Amita M, Yang Y, Schust DJ, Sadovsky Y, Ezashi T \& Roberts RM 2016 Comparison of syncytiotrophoblast generated from human embryonic stem cells and from term placentas. PNAS 113 E2598-E2607. (https://doi.org/10.1073/pnas.1601630113)

Yagi R, Kohn MJ, Karavanova I, Kaneko KJ, Vullhorst D, DePamphilis ML \& Buonanno A 2007 Transcription factor TEAD4 specifies the trophectoderm lineage at the beginning of mammalian development. Development 134 3827-3836. (https://doi.org/10.1242/dev.010223)

Yan L, Yang M, Guo H, Yang L, Wu J, Li R, Liu P, Lian Y, Zheng X, Yan J et al. 2013 Single-cell RNA-Seq profiling of human preimplantation embryos and embryonic stem cells. Nature Structural and Molecular Biology 20 1131-1139. (https://doi.org/10.1038/nsmb.2660)

Yu P, Pan G, Yu J \& Thomson JA 2011 FGF2 sustains NANOG and switches the outcome of BMP4-induced human embryonic stem cell differentiation. Cell Stem Cell 8 326-334. (https://doi.org/10.1016/j. stem.2011.01.001)

Zhao GQ 2003 Consequences of knocking out BMP signaling in the mouse. Genesis 35 43-56. (https://doi.org/10.1002/gene.10167)

Received 6 September 2019

First decision 5 November 2019

Revised manuscript received 7 April 2020

Accepted 17 April 2020 